\title{
Monitoring Vaginal Electrical Impedance in Bangladeshi Water Buffaloes During Postpartum Period
}

\author{
Nasrin Sultana Juyena ${ }^{1, *}$, Mahmudul Hassan ${ }^{1}$, Habibur Rahman Mollah ${ }^{1}$ and \\ Shushanto Kumar Rabidas ${ }^{2}$
}

${ }^{1}$ Department of Surgery and Obstetrics, Bangladesh Agricultural University, Mymensingh-2202, Bangladesh

${ }^{2}$ Lal Teer Animal Breeding House, Lal Teer Livestock Development Limited, Bangladesh

\begin{abstract}
The achievement of early cyclicity and pregnancy after calving are of vital importance for sustainable buffalo farms, for which proper detection of oestrus and correct time of Al are necessary. Vaginal electrical impedance (VEI) observation using heat detector was used to identify estrus in buffalo cows during post-partum period. In the first group, 12 buffalo cows with post-partum $>300$ days were synchronized with OVSYNCH protocol and VEI was recorded at different stages of synchronization protocol. VEI values decreased significantly $(P<0.01)$ during second administration of $\mathrm{GnRH}$ in both pregnant and non-pregnant buffalo cows and it was indicative for the presence of oestrus. Higher VEI values were obvserved at second administration of $\mathrm{GnRH}$ and $\mathrm{Al}$ in non-pregnant group than the pregnant group. In second group, 8 buffalo cows with a post-partum period 40 to 96 days were used to record VEI daily. Lower VEI values

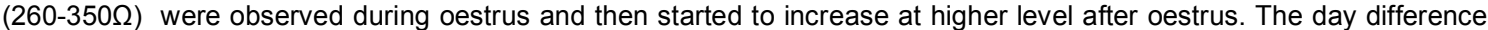
between two successive lower/higher values of "VEI waves" ranged from 17-25 days, which might indicate the oestrous cycle in buffalo cows. Moreover, physical signs such as colour of vulva, mucus were less intensive in buffalo cows of second experiment. The study suggests that the measurement of vaginal impedance could serve as an indicator of the oestrus in buffalo cows and daily impedance measurements are necessary to confirm the stages of the estrous cycle.
\end{abstract}

Keywords: Buffaloes, vaginal electrical impedance, oestrus, post-partum period.

\section{INTRODUCTION}

Buffaloes act as a reliable 'living bank' to serve the immediate needs of the rural masses in several communities in Bangladesh. Despite its importance as a tool for economic growth and poverty alleviation in rural areas of Bangladesh, they are much neglected till now. Buffaloes of Bangladesh have been recognized to possess low reproductive performance [1]. Buffalo cows rarely show mounting behavior [2] and variable duration of estrus (6-64 h) making the prediction of time of ovulation difficult. Moreover, the period of postpartum anoestrous is usually longer in buffalo than in cattle under comparative management conditions [3]. Postpartum anoestrus is a major constrain for successful breeding program in dairy herd. This condition is very serious in buffalo cows due to covert sign of oestrus. Farm personnel can detect heat in about $20-35 \%$ of animals. It is stated that high percentage of buffalo cows show silent oestrus, the longer period between calving and postpartum cyclicity [4]. Silent oestrus is a common problem in buffaloes even under good management and non-stressful periods of the year [5]. Moreover, the different duration of oestrous (4 to $64 \mathrm{~h}$ ) impedes the exact detection of ovulation and results in limited application of $\mathrm{Al}$ in buffaloes [6]. To overcome this problem oestrus

*Address correspondence to this author at the Department of Surgery and Obstetrics, Bangladesh Agricultural University, Mymensingh-2202, Bangladesh; Tel: +8801759674267; Fax: +8809161510;

E-mail: juyenahabib@yahoo.com detector can be used to observe vaginal electrical impedence (VEI). Understanding and investigating VEI "waves" as a functional unit during the oestrous cycle, could facilitate the development of value indicating oestrus.

The Oestrous Detector monitors changes in electrical resistance of the vaginal mucus. Oestrous Detector is responsive to the hormonal changes that coincide with oestrus and is a much simpler and more efficient process [7]. Differences in VEI readings resulted from the oestrous cycle correspond to its phases, providing vital information for efficient and effective breeding. However, there is little study on VEI in water buffaloes in the world. Moreover, this is first study on VEI of buffaloes in Bangladesh. The present experiment was performed to study VEI at different stages of OVSYNCH synchronization protocol and to monitor VEI to detect oestrus and oestrous cycle in buffalo cows during post-partum anoestrus.

\section{MATERIALS AND METHODS}

Twenty Bangladeshi water buffaloes with postpartum anoestrus were used. Buffaloes were divided into two groups. In group 1, twelve water buffalo cows with postpartum period more than 365 days (according to owner complain) were selected from Kanihari village of Trishal upazila, Mymensingh, Bangladesh and synchronized during September 2013. The body condition score of the buffalo cows varied from 3.0 to 
4.0 (1.0 to 5.0 scale) and they were free from any detectable reproductive problems. The age of the buffaloes ranged from 5 to 12 years and their parity ranged between 1 and 4 . The Ovsynch protocol was administered regardless of the stage of oestrous cycle in animals. Each animal was treated with hormones at 5.00 PM afternoon. For oestrous induction, GnRH analogue-Gonadorelin (5ml Ovurelin inj., Bomac Laboratories Ltd., New Zealand) was administered at D0. PGF $_{2}$-Cloprostenol(2ml Ovuprost inj., Bomac Laboratories Ltd., New Zealand) at D 7, which was followed by injection of $\mathrm{GnRH}(2.5 \mathrm{ml}$ Ovurelin inj.) at D9. All hormones were injected intramuscularly in hip region. At 20-22 hours after second gonadorelin injection, $\mathrm{Al}$ of buffaloes was carried out by a trained $\mathrm{Al}$ technician using frozen semen from an Italian Mediterranean bull of known high fertility. The frozen semen was imported from Italy (COFA, Agricultural Cooperative Society, Orezola - 26048, Tidolo sigh of Cremona, Italy). Post-thaw sperm motility was $50-60 \%$. Fixed time $\mathrm{Al}$ was done without considering the onset of prominent oestrus signs. However, some oestrous signs were observed such as, reddish vestibules, swollen vulva with marked edema in vulva lips and clear mucus hanging from the vulva. VEI was measured with Draminski ${ }^{\circledR}$ probe after administration of $P G 2 \alpha$, after administration of second dose of $\mathrm{GnRH}$ and before $\mathrm{Al}$ for proper detection of oestrous condition in buffaloes. Pregnancy diagnosis was performed by observing embryos with transrectalul trasonography using real-time B-mode ultrasound (Tringa Linear $\mathrm{VET}^{\circledR}$, Esaote Pie Medical, Genova, Italy) equipped with a $7.5 \mathrm{MHz}$ linear probe, between Day $40-45$ after insemination.

In group-2, eight buffalo cows with postpartum period from 40 to 96 days were selected from a private farm "LalTeer Animal breeding House", of LalTeer Livestock Development Limited at Bhaluka, Mymensingh, Bangladesh. The impedance was measured once daily up to 37 days. Prior to using the probe of the estrous detector was washed in $1 \%$ potassium per manganate (PPM) solution. Then the probe was inserted into the vagina and was placed aside either left or right to take reading from the vaginal wall. The reading was visible on the screen. Reading was taken three times and the average of three reading was noted. Care was taken to insert the probe at same length each time. To maintain the same length a mark was given on the probe by a marker.

\section{Statistical Analysis}

All data of Group-1 were analyzed in GLM (General Linear Model) in statistical software SPSS 12. Difference in values were measured by two ways ANOVA (Analysis of Variance), where treatment for synchronization protocols were considered as independent variable and values of VEI and pregnancy rate were considered as dependent variables. Differences were considered significant at $P<0.05$. Values were presented as means and S.E.M. For Group-2 descriptive analysis was performed.

\section{RESULTS}

This is the first study on VEI of buffalo cows by heat detector in Bangladesh. VEI values recorded at different stages of the oestrus synchronization protocol are presented in Table 1. It was observed that VEI values decreased very significantly $(P<0.01)$ during second administration of $\mathrm{GnRH}$ in both pregnant and non-pregnant buffalo cows. Whereas, VEI values increased significantly $(P<0.05)$ in pregnant animals during AI.On the other hand, VEI values slightly increased at the time of $\mathrm{Al}$ non-pregnant (Table 1). Moreover, VEI recorded before administration PGF2 $\alpha$ was comparatively higher in pregnant buffaloes $(403.5 \pm 18.2 \Omega)$ in comparison to non-pregnant buffaloes (310.1 $\pm 15.7 \Omega)$. In contrast, higher VEI values recorded during second administration of $\mathrm{GnRH}$ and $\mathrm{Al}$ in non-pregnant buffaloes compared to pregnant buffaloes.

Typical changes in VEI values of individual buffalo cow during study period are presented in Figures 1-8.

Table 1: Values (mean \pm SEM) of Vaginal Electrical Impedence (VEI-mm $\Omega$ ) in Pregnant and Non-Pregnant Buffaloes in Group-1

\begin{tabular}{|c|c|c|c|}
\hline Treatment & Pregnant (58.3\%) & Non pregnant (41.7\%) & P values \\
\hline \hline Administration of PGF & $403.5 \pm 18.2^{\star \star^{a}}$ & $310 \pm 15.7^{\mathrm{a}}$ & 0.002 \\
\hline Administration of GnRH & $180.5 \pm 7.2^{\mathrm{b}}$ & $216.1 \pm 10.3^{\star^{\mathrm{b}}}$ & 0.004 \\
\hline During Al & $200 \pm 19.2^{\mathrm{c}}$ & $221 \pm 11.7^{*^{\mathrm{b}}}$ & 0.04 \\
\hline
\end{tabular}

Symbol indicates significant difference between columns; a,b,c indicate significant difference within rows.

*significant at $P<0.05,{ }^{* *}$ significant at $P<0.01$. 


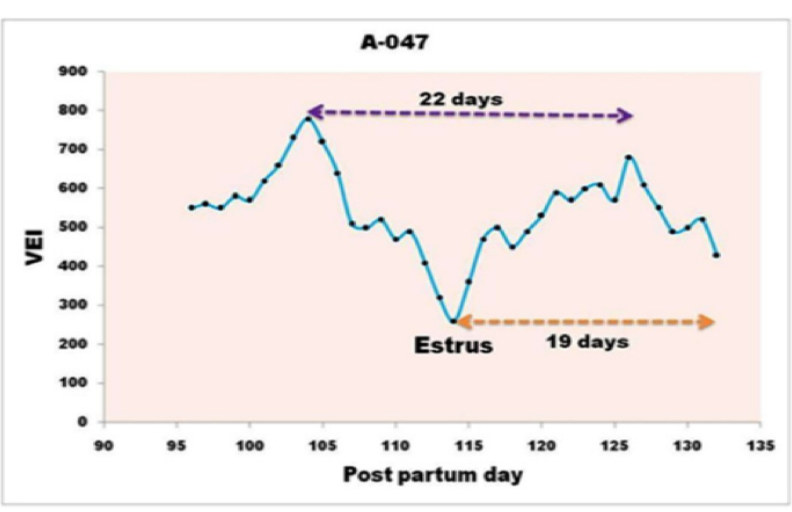

Figure 1: VEI was recorded from 96 days postpartum in buffalo No-047 and VEl was $550 \Omega$. AT 104 postpartum it increased to $780 \Omega$ and then started to decrease and reached at lowest value $260 \Omega$ at114 postpartum when oestrus was observed. Then again increasd to $680 \Omega$ at day 126. Day difference between two highest peaks was 22 days which might indicate oestrous cycle of this buffalo.

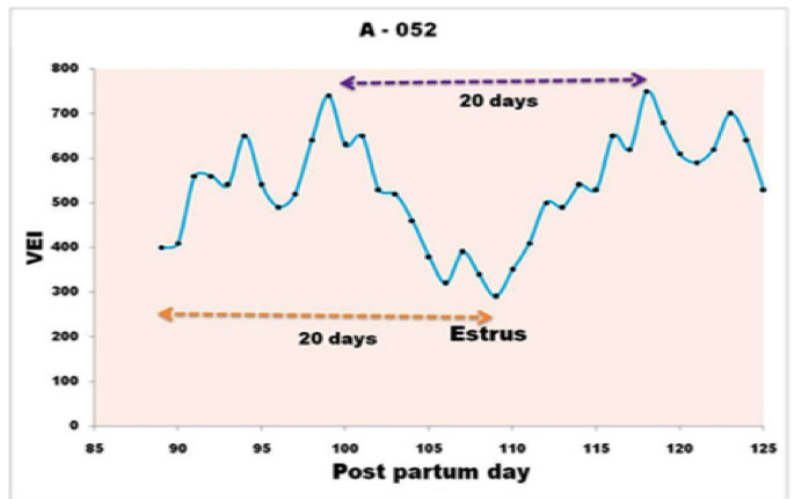

Figure 2: VEI was recorded from 89 days postpartum in buffalo No-052 and VEI was $400 \Omega$. AT 99 postpartum it increased to $740 \Omega$ and then started to decrease and reached at lowest value $290 \Omega$ at 109 postpartum when buffalo was in oestrus. Then again increasd to $750 \Omega$ at day 118.Day difference between two highest peaks was 20 days.

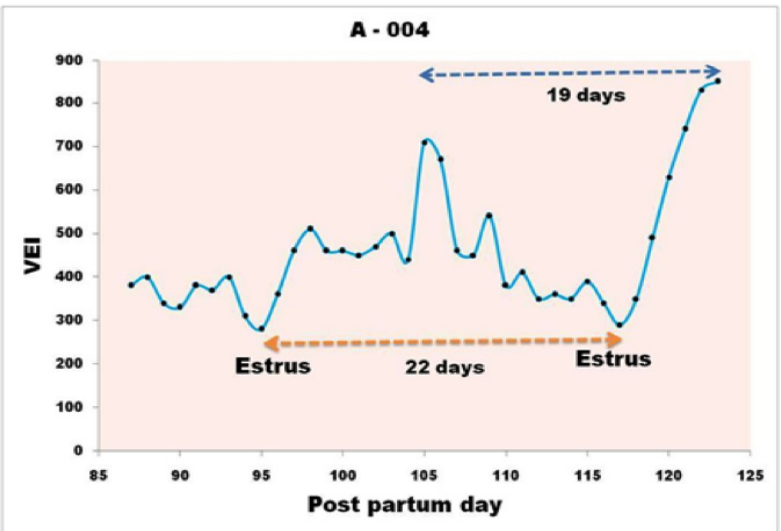

Figure 3: VEl was recorded from 87 days postpartum in buffalo No-004 and VEI was $380 \Omega$. AT 95 postpartum it decreased to $280 \Omega$ when buffalo was in oestrus and then started to increase and reached highest peak $710 \Omega$ at 105 postpartum. Then VEI value reached to $290 \Omega$ at day 117 . Day difference between two lowest values was 22 .

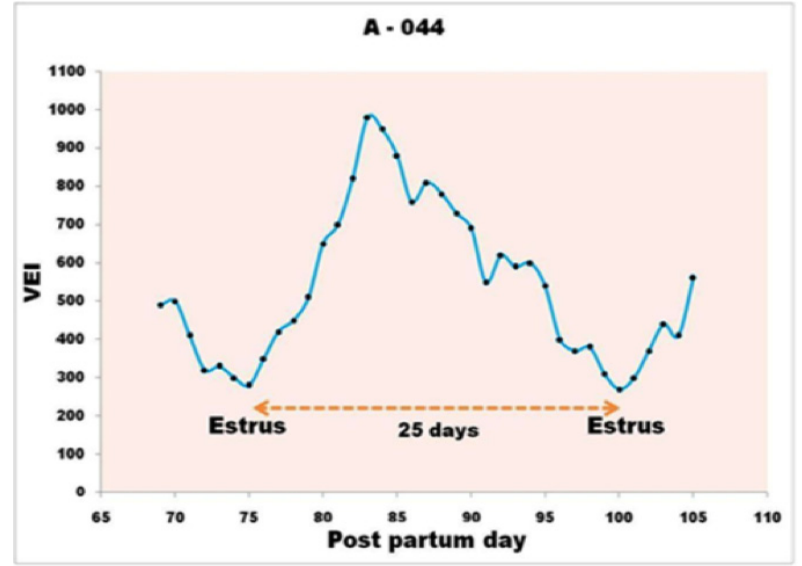

Figure 4: VEl was recorded from 69 days postpartum in buffalo No-044 and VEI was $490 \Omega$. AT 75 postpartum it decreased to $280 \Omega$ and then started to increase and reached highest peak $980 \Omega$ at 83 postpartum. Then VEI value decreased to $270 \Omega$ at day 100 . Day difference between two lowest peaks was 25 .

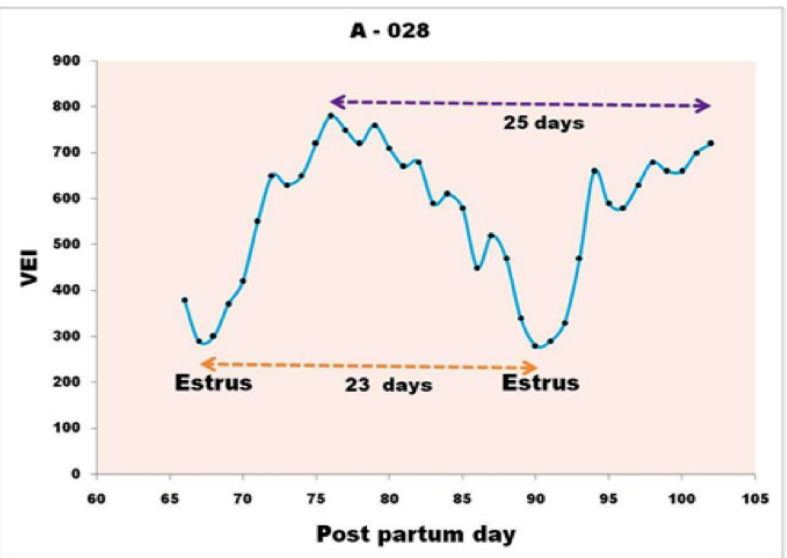

Figure 5: VEl was recorded from 66 days postpartum in buffalo No-028 and VEI was $380 \Omega$. AT 67 postpartum it decreased to $290 \Omega$ when buffalo was in heat.The second lower VEI value was $280 \Omega$ observed at day. Day difference between two lower values was 23 .

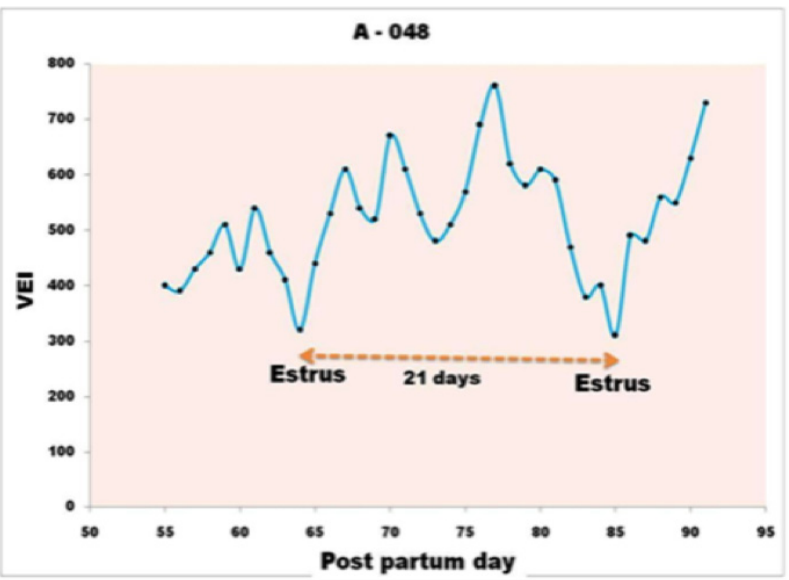

Figure 6: shows VEI values recorded from 55 days postpartum in buffalo No-048 and VEI was $400 \Omega$.Two lower values were $320 \Omega$ and $310 \Omega$. Day difference between two loweer values was 21 . 


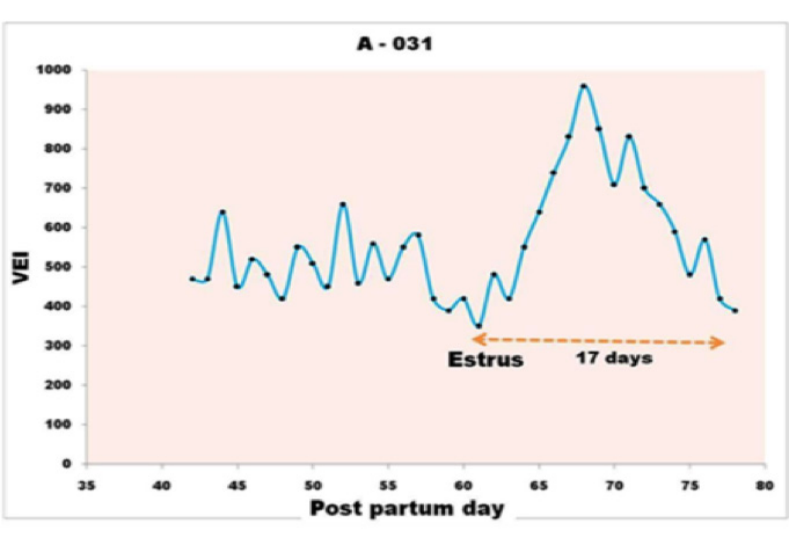

Figure 7: VEI was recorded from 42 days postpartum in buffalo No-031 and VEI was $470 \Omega$. AT day 61 postpartum it decreased to $350 \Omega$ when buffalo was in heat. Oestrus was observed at day 78 when lower value was $390 \Omega$. Day difference between lower values was 17 .

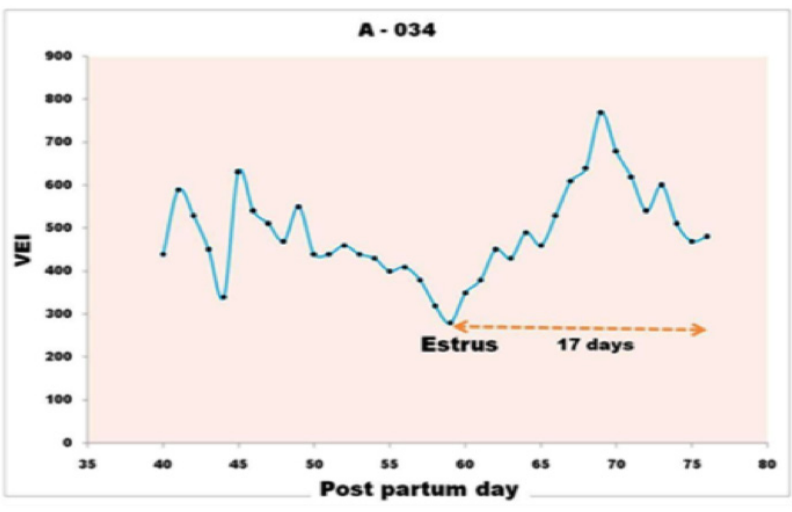

Figure 8: VEl was recorded from 40 days postpartum in buffalo No-034 and VEI was $440 \Omega$. AT day 59 postpartum it decreased to $280 \Omega$ and then started to increase and reached highest peak $770 \Omega$ at day 69 postpartum. Then again fallen down at day 76 to $480 \Omega$. Day difference between two lower values was 17 .

In general, lower VEI values were observed during oestrus and then increased to a high level after oestrus. Resistance remained high near the next heat and then it dropped again. This is worthy to mention that daily VEI values had been observed daily up to 37 days to record the minimum level of resistance and the moment when a distinct rise in resistance occurred. The day difference between two successive lower/higher peaks in VEI waves ranged from 17-25 days which might indicate the oestrous cycle in buffalo cows. Two lower values were observed in buffalo No. 004, 044, 028, 048, 031 and 034, whereas, higher two peaks were considered in buffalo No. 047 and 052 .

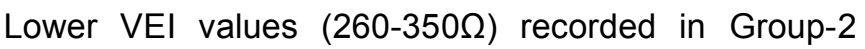
supposed to be indicative of oestrus and was higher when we compared to VEI observed at the administration of second $\mathrm{GnRH}$ in the Group-1. Individual variation was existed. In addition, the intensity of heat occurred was also recorded. Physical signs i.e. changes in vulva colour and mucus were less marked in buffaloes of Group-2.

\section{DISCUSSION}

Heat detection technique based on animal behaviour can produce both false positives and false negatives [8]. Most detection methods are not suitable in herd practice in Bangladesh. Detection method should combine robustness, cost and herd feasibility. For this reason, the experiments were performed to study VEI with heat detector probe to monitor oestrus and oestrus cycle in buffalo cows during post-partum. In Group-1, it was observed that VEI decreased very significantly $(P<0.01)$ during second administration of $\mathrm{GnRH}$ and increased during Al. Variation existed in VEI values of pregnant and non-pregnant buffaloes recorded at different stages of synchronization protocol. It is well known that oestrus occurs $24-48 \mathrm{hrs}$ after intramuscular injection of $\mathrm{PGF}_{2}$ in cattle as well as buffaloes. In OVSYNCH protocol, second dose of $\mathrm{GnRH}$ was administered $48 \mathrm{hrs}$ after injection of PGF and Lower VEI recorded this stage indicated presence of oestrus. Presence of swollen and reddish vulva and mucus strand supports this finding. There is no precise report available on VEI values of buffaloes. Not only that, this is the first study on VEI with two electrodes technique in Bangladesh. We observed that VEI values ranged from $260 \Omega$ to $350 \Omega$ when buffalo was in heat. Research shows that cervical mucus increases in amount and becomes more thinner with elastic during the follicular phase of the oestrous cycle as reported in ewes [9]. During oestrus, oestrogen level rises leading to increased production of adrenocorticotropic and aldosterone hormones. These hormones increase the levels of $\mathrm{NaCl}$ in the vaginal mucous resulting in a significantly lower level of electrical resistance than usual [10]. However, Gupta and Purohit [11] have revealed that vaginal impedance is lowest during the follicular phase and highest during the luteal phase of the oestrous. An inverse relationship exists between vaginal impedance and serum oestradiol in the follicular phase [12]. Moreover, we observed higher VEI values recorded during second administration of $\mathrm{GnRH}$ and $\mathrm{Al}$ in non-pregnant group compared to pregnant group. There is paucity of data regarding VEI values in indigenous water buffaloes in Bangladesh. Gupta and Purohit [11] reported that $\mathrm{Al}$ at a low VEI distinctly improved the conception rate in buffaloes.

Typical changes in VEI of individual buffalo cows were observed daily up to 37 days to record the 
minimum level of resistance and the moment when a distinct rise in resistance occurred. It supports the statement of Aizinbud et al. [13] who stated that daily impedance measurements are necessary to confirm the stages of the oestrous cycle. The difference between two successive lower andlor higher VEI values ranged from 17-25 days, which might indicate the oestrous cycle length in buffalo cows. Result corresponds well with the finding of Jainudeen and Hafez [3] who reported that the duration of the oestrous cycle in buffalo ranged from 17 to 26 days with a mean of around 21 days. Lower VEI values recorded in Group-2 supposed to be indicative of oestrus and was higher when compared to VEI observed at the time administration of second GnRH in Group -1. It is important to point that buffaloes were milked twice per day during the study period. Lactation may increase circulating progesterone concentrations [14] that, in turn, may decrease GnRH-induced LH secretion [15] producing the decreasing ovulation efficiency.

Heat Detector monitors changes in electrical resistance of the vaginal mucus. Measurements are taken simply by properly inserting the probe in the vagina and taking the reading. No prior technical knowledge on the part of the operator is required. Estrous Detector responsive to the hormonal changes and can replace the more costly procedure of progesterone-based pregnancy detection [7]. The impedance technique is one of the tools that could be used for non-invasive monitoring of events occurring in cyclic animals [8]. Electrical impedance is measured by introducing a small alternating electrical current in the limited area of the cervix uteri, vagina, vaginal vestibule or vulva and measuring on its surface the electrical potential difference $[11,16]$. This is worthy to consider some physical factors such as, instability of the contact between the vaginal mucosa and electrodes due to the changes in the tone of the vagina, the entrapment of air in the vagina during insertion of an electrode-bearing probe or unequal hand pressure during taking impedence measure [17].

Externally detectable physical changes around the time of oestrus include swelling of the vulva and reddening of the vestibular mucosa. Mucus secreted from the cervix during oestrus is less copious in buffalo than in cattle. The concentration of oestradiol-17 $\beta$ in blood during the follicular phase of the oestrous cycle also appears to be relatively less in buffalo than that in cattle [18] and this has been suggested as a possible reason for the lesser intensity of oestrus exhibited by buffaloes. Considering these perspective, the measurement of vaginal impedance could serve as an indicator of the follicular and luteal status in cyclic buffaloes.

In this study, the vaginal length was not measured where detector was placed. There might be differences among VEI values taken from different anatomical site of female reproductive tract in buffalo, which need to focus in future. Moreover, hormonal profiles (oestrogen and progesteron level) were not measured to conclude if there is any relationship between VEI and hormones is existed. Moreover, future study should be directed to identify factors that may affect the variability of impedance values in the vagina during the oestrous cycle in buffalo cows. Further study is in progress to detect definite range of VEI, which would allow us to improve our ability to predict heat more precisely by impedance techniques in buffaloes.

\section{REFERENCES}

[1] Alam MGS and Ghosh A. Reproductive patterns of rural buffaloes (Bubalus bubalis) in Bangladesh. Proceedings, Third buffalo Congress, Varna, Bulgeria. 1991; pp. 683-685

[2] Baruselli PS, Carvalho NAT, Henriquez CEP, Amaral A, Nichi $\mathrm{M}$, Reichert, RT. Reduction of hCG dosage in a protocol for synchronization of ovulation for timed artificial insemination during the off breeding season in buffalo. In: Atti 20 Congresso Nazionale sull'Allevamento del Bufalo, Monterontondo-Rome, Italy, 28-30 Agosto. 2003; p. 261-264.

[3] Jainudeen MR, Hafez ESE. Cattle and buffalo. In: Hafez ESE, editor. Reproduction in farm animals. 6th ed., Philadelphia: Lea and Febiger; 1993.

[4] Barile VL. Improving reproductive efficiency in female buffaloes. Livestock Prod Sci 2005; 92: 183-192. http://dx.doi.org/10.1016/j.livprodsci.2004.06.014

[5] Abdallah EB. Improving the reproductive performance of Egyptian buffalo cows by changing the management system. Anim Reprod Sci 2003; 75: 1-8.

http://dx.doi.org/10.1016/S0378-4320(02)00225-7

[6] Neglia G, Gasparrini B, Palo R, Rosa C, Zicarelli L, Campanile G.Comparison of pregnancy rates with two estrus synchronization protocols in Italian Mediterranean buffalo cows. Theriogenology 2003; 60: 125-133. http://dx.doi.org/10.1016/S0093-691X(02)01328-6

[7] Tasal I, Ataman MB, Aksoy M, Kaya A, Karaca F, Tekeli T. Estimation of early pregnancy by electrical resistance values of vaginal mucosa in cows and heifers. Rev Med VetToulouse 2005; 156: 91-15694.

[8] Miranda N, Morais R, Dias M, Viegas C, Silva F, Serôdio C. Bioimplantable impedance and temperature monitor low power micro-system suitable for estrus detection. Procedia Chemistry 2009; 1 : 505-508.

http://dx.doi.org/10.1016/j.proche.2009.07.126

[9] Adams GP, Matter RL, Kastelic JP, Ko JC, Ginther OJ. Association between surges of follicule stimulating hormone and the emergence of follicular waves in heifers. J Reprod and Fert 1992; 94: 177-188.

http://dx.doi.org/10.1530/jif.0.0940177

[10] Fehring RJ. A comparison of the ovulation method with the CUE ovulation predictor in determining fertile period. J Amer Aca nurse Pract 1997; 8: 461-466.

http://dx.doi.org/10.1111/j.1745-7599.1996.tb00604.x 
[11] Gupta KA, Purohit GN. Use of vaginal electrical resistance (VER) to predict estrus and ovarian activity, its relationship with plasma progesterone and its use for insemination in buffaloes. Theriogenology 2001; 56: 235-245.

http://dx.doi.org/10.1016/S0093-691X(01)00559-3

[12] Fazleabas AT, Segraves MM, Khan FS. Evaluation of salivary and vaginal electrical resistance for determination of the time of ovulation. Int J Fert 1990; 35: 106-111.

[13] Aizinbud E, Schindler H, Adam L. Impedometry of the bovine vagina and vulva for oestrusdetection: present state of research and prospects. Refuah Vet 1980; 37: 156-162.

[14] Wiltbank MC, Lopez H, Sartori R, Sangsritavong S, Gumen A. Changes in reproductive physiology of dairy cows due to elevated steroid metabolism. Theriogenology 2006; 65: 1729.

http://dx.doi.org/10.1016/j.theriogenology.2005.10.003
[15] Dias FC. Effect of progesterone on GnRH-mediated $\mathrm{LH}$ release, oocyte quality and fertility in cattle. M.S. Thesis, University of Saskatchewan, Canada, 2008.

[16] Ginther OJ, Beg MA, Donadeu FX, Bergfelt DR. Mechanism of follicle deviation in monovular farm species. Anim Reprod Sci 2003; 78: 239-257.

http://dx.doi.org/10.1016/S0378-4320(03)00093-9

[17] Lehrer AR, Lewis GS, Aizinbud E. Electrical resistance of genital tissues in reproductive events in cows and its possible on-farm applications: a review. Wien Tiera"rztIMschr 1991; 78: 317-322.

[18] Roy KS, Prakash BS. Plasma progesterone, oestradiol-17 $\beta$ and total oestrogen profiles in relation to oestrousbehaviour during induced ovulation in Murrah buffalo heifers. J Anim Physiol Anim Nutr 2009; 93: 486-495. http://dx.doi.org/10.1111/j.1439-0396.2008.00830.x 